\title{
STATEMENT FOR TRAVELLERS AND YELLOW FEVER
}

\section{Preamble}

The Committee to Advise on Tropical Medicine and Travel (CATMAT) provides the Public Health Agency of Canada with ongoing and timely medical, scientific, and public-health advice relating to tropical infectious disease and health risks associated with international travel. The Agency acknowledges that the advice and recommendations set out in this statement are based upon the best current available scientific knowledge and medical practices, and is disseminating this document for information purposes to both travellers and the medical community caring for travellers.

Persons administering or using drugs, vaccines, or other products should also be aware of the contents of the product monograph(s) or other similarly approved standards or instructions for use. Recommendations for use and other information set out herein may differ from that set out in the product monograph(s) or other similarly approved standards or instructions for use by the licensed manufacturer(s). Manufacturers have sought approval and provided evidence as to the safety and efficacy of their products only when used in accordance with the product monographs or other similarly approved standards or instructions for use.

Members: Dr. A. McCarthy (Chair); Dr. A.K. Boggild; Dr. J. Brophy; Dr. Yen-Gaing Bui; Dr. M. Crockett; Dr. W. Ghesquiere; Dr. C. Greenaway; Ms. A. Henteleff; Dr. Michael Libman; Dr. P.J. Plourde Dr. P. Teitelbaum.

Ex-Officio Representatives: Dr. P. Charlebois; Dr. P. McDonald; Dr. S. Schofield; Dr. M. Tepper.

Liaison Representatives: Dr. G. Brunette; Dr. C. Hui.

Member Emeritus: Dr. C.W.L. Jeanes.

${ }^{\dagger}$ This statement was prepared by P. Charlebois and approved by CATMAT. 


\section{Table of Contents}

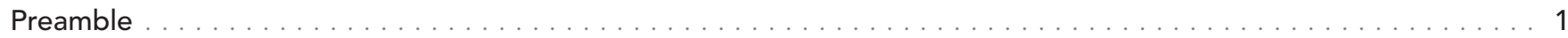

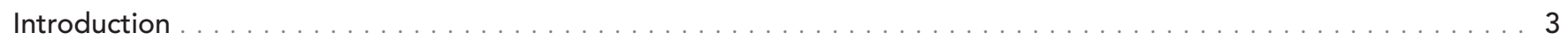

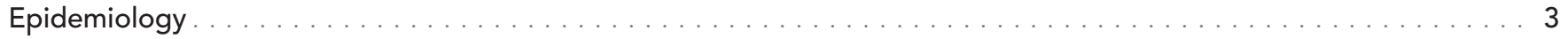

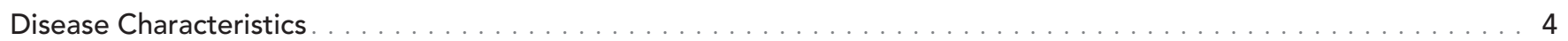

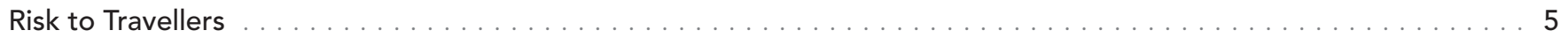

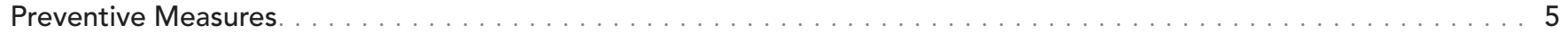

International Health Regulations and yellow fever control measures . . . . . . . . . . . . . . .

Yellow fever vaccination in Canada . . . . . . . . . . . . . . . . . . . . . 6

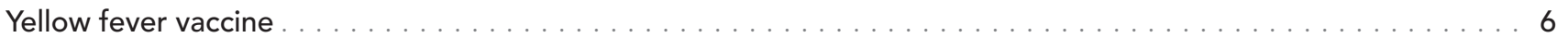

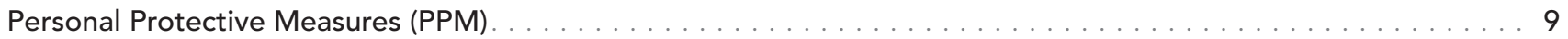

Potential Consequences of Inappropriate Documentation . . . . . . . . . . . . . . . . .

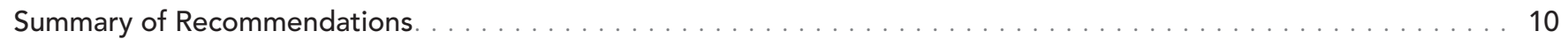

Table 1: Strength and quality of evidence of summary $\ldots \ldots \ldots \ldots$

Table 2: Recommendations for the use of yellow fever vaccine by population . . . . . . . . . . . . . . 10

Appendix 1: Yellow Fever Risk Areas. . . . . . . . . . . . . . . . . . . . . . . . . 11

Appendix 1a: Yellow fever risk classification criteria, 2011 . . . . . . . . . . . . . . . . 11

Appendix 1b: Countries with risk of yellow fever transmission by continent, $2011 \ldots \ldots$

Appendix 1c: Yellow fever vaccination recommendations in Africa, 2010 . . . . . . . . . . . . . . . . . 12

Appendix 1d: Yellow fever vaccination recommendations in the America, 2010 . . . . . . . . . . . . . . 13

Appendix 2: Yellow Fever Vaccination Centres in Canada . . . . . . . . . . . . . . . . . . . . . . . 14

Appendix 2a: Example of a Completed Copy of the International Certificate of Vaccination

or Prophylaxis Issued by the Public Health Agency of Canada . . . . . . . . . . . . . . . . 15

Appendix 2b: Example of a Completed Copy of the Certificate of Medical Contraindication to Vaccination Issued by the Public Health Agency of Canada . . . . . . . . . . . . . . . . . 16

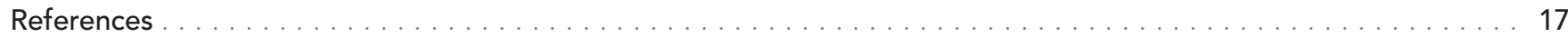




\section{Introduction}

Yellow fever is a vaccine-preventable, vector-borne illness caused by a virus from the family Flaviviridae. In its most severe form, it causes a hemorrhagic fever which has a high case fatality rate despite aggressive supportive measures. Yellow fever virus is the prototype of the flavivirus genus, made up of approximately 70 other viruses, including dengue fever virus, Japanese encephalitis virus, and West Nile virus, to name a few (1-3).

The World Health Organization (WHO) estimates that approximately 200,000 yellow fever cases occur per year, resulting in up to 30,000 deaths. The disease is presently endemic and intermittently epidemic in South America and Africa $(1 ; 4)$.

\section{Epidemiology}

Yellow fever is endemic and intermittently epidemic in parts of Africa and South America. While the mosquito vectors are present in Asia, there have been no documented cases of transmission on this continent. There are three transmission cycles which describe the occurrence of yellow fever:

1. Jungle or Sylvatic transmission: occurs in jungle environments where multiple mosquito species (including Aedes spp., Haemagogus spp.) transmit the virus between non-human primate hosts. As transmission is ongoing, humans are infected sporadically if and when exposed to jungle mosquitoes. Humans living and working within or near the jungle are at risk of acquiring the disease within the jungle/sylvatic cycle $(1 ; 3)$;

2. Urban transmission: occurs in more metropolitan areas where the Aedes aegypti mosquito acts as the main vector. Urban yellow fever cycles usually result in an epidemic after the virus has been introduced either by an infective mosquito or a human carrying the yellow fever virus. Due to the greater density of people in urban areas, urban yellow fever cycles can result in explosive epidemics $(1 ; 3)$;

3. Intermediate transmission: occurs in smaller rural villages, where humans and monkeys live in close proximity to each other, and semi-domestic mosquitoes (Aedes spp.) infect both human and primates with the yellow fever virus. This cycle typically produces smallscale epidemics and is seen only in Africa.
Historically, yellow fever has been an important pathogen. Much of the early research into the disease was prompted by the outbreaks during the building of the Panama Canal and the Spanish-American War. However, yellow fever epidemics plagued North America into the early part of the $20^{\text {th }}$ century. Aggressive vector control measures and eventually vaccination eliminated urban transmission in North America and Europe (5).

Vaccination of susceptible populations has dramatically decreased infection in human populations. Because yellow fever virus is spread by a mosquito vector, mosquito control and personal protective measures against mosquito bites are also an important part of preventing yellow fever infection, and are used in tandem with vaccination to lessen the impact of disease in endemic areas (1;6-9).

The most recently published data available from the WHO indicate that in 2010 there were 42 cases of yellow fever reported to WHO. Nine yellow fever outbreaks were reported in six countries. In Central and West Africa, a total of 20 cases with no deaths were reported in 2010 from the following countries: Cameroon ( $n=7)$, Democratic Republic of the Congo ( $n=2)$, Guinea ( $n=9)$, and Senegal $(n=2)$. In South America, 22 confirmed cases with 17 deaths were reported during 2010 (Bolivia, $\mathrm{n}=2$; Brazil, $\mathrm{n}=2$; Peru, $\mathrm{n}=18$ ); the case-fatality rate was $77.3 \%(6 ; 10)$. True incidence rates in both South America and Africa are believed to be 10 to 50 fold higher than what is officially recorded due to high levels of underreporting, surveillance and diagnostic limitations, and infections with little to no clinical symptoms (2).

Nine cases of yellow fever were reported in unvaccinated international travellers from the United States and Europe between 1970 to 2010. Four of these cases were acquired in South America (Brazil = 3, Venezula $=1$ ), and five were acquired in Africa (Senegal = 2, Ivory Coast $=1$, the Gambia $=1$, West Africa = 1) (7;11-15). In 1987, there was one reported case of yellow fever in a vaccinated traveller from Spain who had travelled in western Africa. To date, there have not been any diagnosed yellow fever cases in returned Canadian travellers (16). 
As yellow fever is maintained within a non-human primate host population (as demonstrated by the jungle transmission cycle), eradication of the disease is impossible. It also makes global monitoring of the disease difficult $(2 ; 11)$. Concerns have also been expressed in recent years that environmental, geographical, and human-driven changes may factor into the distribution of yellow fever: changing rainfall patterns affect mosquito populations and locations, growing deforestation increases human proximity to natural yellow fever hosts (i.e. primates) and may increase number of sylvatic and/or intermediate outbreaks. Increased urbanization may allow for more concentrated human epidemics, and increased international travel and trade creates the theoretical possibility of importation or exportation of the disease $(11 ; 17-19)$.

In 2011, the WHO published revised yellow fever vaccination recommendations for travellers, as a result of consultations with international travel medicine experts and a comprehensive review of available data (20;21). The revisions included:

- Updated criteria for the designation of areas with risk of yellow fever virus activity. The classification of geographical areas, according to risk of transmission of yellow fever, was outlined in four categories: (i) endemic, (ii) transitional, (iii) low potential for exposure, and (iv) no risk. For definitions for each category, refer to Appendix 1a.

\section{Disease Characteristics}

The clinical presentation of the disease varies in severity from asymptomatic to fatal. For those who present with symptoms, yellow fever is typically characterized by an acute onset after an incubation period of three to six days. Initial symptoms include fever, chills, headache, backache, muscle pain, joint pain, nausea, vomiting, photophobia, mild jaundice, and epigastric pain. Faget's sign may be present (slow weak pulse, contrasting with high fever). Jaundice worsens as disease progresses (3;4). In an estimated $85 \%$ of yellow fever cases, the disease resolves itself at this time (7). For others, after a brief remission lasting anywhere between hours to a day, conditions worsen and the disease advances in the liver eventually leading to renal failure, haemorrhagic symptoms, and thrombocytopenia. Treatment is symptomatic and supportive $(3 ; 4 ; 7)$.
- Countries and geographic areas with a risk of yellow fever transmission were reassessed with the new criteria, and vaccine recommendations were made based on the level of risk.

- Yellow fever vaccination is recommended for travellers visiting endemic or transitional areas.

- Yellow fever vaccination is generally not recommended for travel to areas with low potential for exposure; however, vaccination may be considered for a small subset of travellers whose itineraries would place them at an increased risk for exposure to yellow fever virus (e.g., prolonged travel, heavy exposure to mosquitoes, inability to avoid mosquito bites).

- Yellow fever vaccination is not recommended for travellers whose itineraries are restricted to areas with no risk.

- Revision of maps to illustrate yellow fever vaccination recommendations rather than yellow fever risk. For maps, refer to Appendix 1c and Appendix 1d.

In travellers, clinical features and patient history (travel dates, locations, and activities) usually inform the initial diagnosis (7). Diagnosis is confirmed in both travellers and non-travellers by the isolation of virus from blood by inoculation of special media (1). Techniques identifying antigen or nucleic acid components using enzyme linked immunosorbent assay (ELISA) or polymerase chain reaction (PCR) tests are also used (22;23). Serological cross reaction may occur with other flaviviruses, and should be considered during diagnosis (3). Also, virus is sometimes difficult to isolate after the fourth day of illness (7). All yellow fever diagnoses made in Canada are required to be reported to public health authorities, as yellow fever is both a notifiable disease in Canada, and internationally, as defined by the 2005 International Health Regulations (IHR) (19). 


\section{Risk to Travellers}

Estimating the risk of acquiring yellow fever in the individual traveller is very difficult, as it is dependent on many variables including destination, season, occupational and recreational activity, and local yellow fever virus activity $(11 ; 20 ; 21)$.

\section{Destination:}

A traveller's destination factors into yellow fever risk in many ways. Yellow fever is unique amongst communicable diseases in that it has international regulations that govern its control (See Preventive Measures). These are set out by the World Health Organization in the form of International Health Regulations (IHR) last updated in 2005. Some countries require travellers to be vaccinated against yellow fever to enter the country, as outlined in the IHR. $\mathrm{IHR}$ requirements also stipulate that proof of vaccination is necessary for travellers arriving from or through a country where yellow fever is endemic. Some countries where yellow fever circulates do not require vaccination for entrance (e.g. Brazil) and therefore unvaccinated travellers may be at greater risk, especially if visiting a yellow fever risk area.

\section{Season:}

The number of mosquitoes generally increases during and following a "wet season"(2). Vertical transmission occurs with the yellow fever virus from female mosquito to her larvae $(2 ; 5)$. This can increase the risk for travellers as more vectors may be present to transmit disease.

\section{Preventive Measures}

\section{International Health Regulations and yellow fever control measures}

Yellow fever is unique among diseases in that there are international health regulations which outline the requirements for proof of vaccination when travelling to specific countries, or when entering some countries from a yellow fever endemic region (19). As stated by the $\mathrm{WHO}$ in International Travel and Health (27), there are two main objectives to yellow fever vaccination:

- To prevent the international spread of the disease by protecting countries from the risk of importing or spreading the yellow fever virus. These are mandatory requirements established by the country.

\section{Occupational and recreational activity:}

Activities which expose travellers to the outdoors during prime mosquito biting hours can increase risk of yellow fever transmission (24).

\section{Local yellow fever virus activity:}

Yellow fever virus activity fluctuates. As surveillance infrastructure is poor in many countries where yellow fever is found, and difficulties are inherent in closely monitoring non-human hosts, this variable is particularly difficult to quantify $(11 ; 17 ; 18)$. There have been sporadic outbreaks in the last few years in Africa and South America $(6 ; 9 ; 10 ; 25 ; 26)$.

These risks should all be taken into consideration by travellers and travel health practitioners during pre-travel consultation to determine the need for yellow fever vaccination. As with many aspects of travel medicine, a clinical decision requires up-to-date epidemiologic data to make informed choices.

The careful examination of risk is important when dealing with those populations in which there is a higher risk of adverse events with vaccination (See section on Vaccine and Special Populations). When counselling these patients, accurate information as to travel itinerary, activity within the area of risk and up-to-date yellow fever epidemiology is required. This information is used to weigh the risks and benefits to determine the need for vaccination on a case by case basis.
- To protect individual travellers who may be exposed to yellow fever infection.

For this reason, the traveller may present to a health care professional with a request for yellow fever vaccination from a travel agency or tour provider without specifics as to why the vaccine is required. A proper risk assessment needs to be carried out as to the actual itinerary of the traveller (see section on Risk to Travellers) to determine whether the need is for actual traveller protection or to correspond with the entry requirements of the destination country. 
Global control measures have been very successful in eliminating the risk of yellow fever in many areas. However, many regions (e.g. Southeast Asia) have both the mosquito vector and non-human primates that are required to support a possible yellow fever outbreak. It is for this reason that a number of countries require proof of yellow fever vaccination as an entry requirement, despite no reported disease within their territory (refer to Appendix 1) (7). These requirements are generally for those travellers arriving from, or who have travelled through, regions with known yellow fever transmission. A recent update from $\mathrm{WHO}$ (27) recommends that a transit of less than 12 hours through an international airport would not put a traveller at risk for contraction of yellow fever. Thus, if the only travel to a region of transmission of yellow fever is such a transit, then it really should not be considered an actual exposure by subsequent destination countries. These recommendations have been published by $\mathrm{WHO}$, but it is the right of each country to define its entry requirements. Travellers should confirm carefully prior to departure.

\section{Yellow fever vaccination in Canada}

Yellow fever vaccines administered in Canada are available only at designated Yellow Fever Vaccination Centres. Presently, the Public Health Agency of Canada designates Yellow Fever Vaccination Centres across the country (28). A list of Yellow Fever Vaccination Centres can be obtained on the Agency's website (www.phac-aspc.gc.ca/tmp-pmv/yf-fj/ index-eng.php). One exception to this is the Yellow Fever Vaccination Centres with the Canadian Forces that are designated by the Directorate of Force Health Protection. These Centres administer the yellow fever vaccine and provide an International Certificate of Vaccination or Prophylaxis (see Appendix 2a) that will accompany the traveller. The certificate of vaccination is valid for a period of 10 years, commencing 10 days after the initial vaccination or immediately upon re-immunization. Re-immunization should be considered at 10 year intervals; however there is evidence that seroconversion bestows longer protection and may be lifelong (29).

For those people who cannot be vaccinated, the traveller may be provided with a waiver outlining the medical reason for not receiving the vaccination. This can be documented on the letterhead of the health care site or on a Certificate of Medical Contraindication to Vaccination (see Appendix 2b), that the Agency issues to Yellow Fever Vaccination Centres.

\section{Yellow fever vaccine}

The yellow fever vaccine is a live attenuated preparation grown in chick embryos inoculated with the 17D yellow fever virus strain. Worldwide, vaccine lineages include the 17D-204, 17-213 and the 17DD types (1). In Canada, there is only one yellow fever vaccine approved for use: the 17D-204 lineages, marketed as YF-VAX®, produced by Sanofi Pasteur Limited (30). YF-VAX® is lyophilized and contains sorbitol and gelatin as stabilizers. There is no preservative in the vaccine or the accompanying diluent (30).

According to Sanofi Pasteur, the vaccine must be maintained at temperatures between two and eight degrees Celcius $\left(2^{\circ}-8^{\circ} \mathrm{C}\right)(30)$. This requires closely monitored refrigeration to ensure that the vaccine maintains viability. The vaccine should not be allowed to freeze, nor should the diluent (30). Once reconstituted, the vaccine should be refrigerated and used within one hour. All vaccine not used within the one hour window should be discarded (30).

The yellow fever vaccine may be simultaneously administered with the following vaccines: measles, polio (oral polio vaccine), diphtheria, tetanus, pertussis, hepatitis $B$, hepatitis A, oral cholera, and oral or parenteral typhoid. Different syringes are to be used and the vaccines are to be injected at different sites on the body. When not given simultaneously, live vaccines should be administered at least four weeks prior to or after the yellow fever vaccination. This recommendation is based on the assumption that interferon released in response to the first vaccine may have a temporary inhibitory effect on other live virus vaccines (1).

\section{Risks associated with vaccination}

In the last few years, a number of rare, but serious reactions to yellow fever vaccination have been documented (31-35). This has led to a review of the various vaccine preparations and their use and indications $(1 ; 30 ; 35)$. As with any therapy, there are major and minor adverse events associated with a certain percentage of the population receiving the intervention. The goal of any therapy is to employ it only when the benefits of the intervention outweigh potential harms.

\section{MILD VACCINE-RELATED ADVERSE EVENTS}

Yellow fever vaccines are generally well tolerated. Reactions to the vaccine are usually mild and transient in nature and include headaches, myalgias and low-grade fevers $(1 ; 7 ; 30 ; 36)$. 
Reports on vaccine safety and efficacy are published in the Canadian Immunization Guide (CIG), the YF-VAX® product monograph, as well by both the Centers for Disease Control and Prevention (CDC) and the World Health Organization (WHO). All report that the vaccine is safe and effective.

Reactions usually begin a few days after vaccination and last five to ten days post dose $(1 ; 7)$. There is a wide variability (2-30\%) in the frequency of report of mild adverse events i.e. headache, myalgia, low-grade fever. Less than one percent of recipients had to curtail daily activities due to an adverse event following vaccination $(30 ; 37)$.

\section{SERIOUS ADVERSE EVENTS}

Although rare, there have been a range of serious adverse events which have been recorded following yellow fever vaccination, including:

- Hypersensitivity reactions: Immediate type hypersensitivity reactions (rash, urticaria, asthma, anaphylaxis) to the yellow fever vaccine can occur. The Vaccine Adverse Event Reporting System (VAERS) in the United States report the rate of 43 adverse events following yellow fever vaccine reported to VAERS per 100,000 doses distributed (38). These are rare events: the $\mathrm{CIG}$ provides rates of one in 250,000 to one in 300,000 (37). Hypersensitivity reactions occur primarily in people with sensitivity to egg proteins and/or chicken $(4 ; 11 ; 37 ; 39 ; 40)$. The gelatin stabilizer used in the vaccine has also been implicated $(1 ; 11 ; 39)$. Therefore, people with allergies to eggs, chicken, or gelatin should not receive the vaccine. Anaphylaxis can also occur in persons with no known allergy to vaccine components. For those individuals with suspected sensitivity and a need for immunization, such persons may be referred to an allergist for evaluation if vaccination against yellow fever is considered (30).

- Yellow fever vaccine associated neurotropic disease (YEL-AND): YEL-AND was once a syndrome characterized by fever and encephalitis in young children. These adverse events were largely reduced once the yellow fever vaccine was no longer administered to children less than six months old (36). YEL-AND now describes a grouping of clinical syndromes: meningoencephalitis, auto-immune involvement of the central nervous system and/or auto-immune involvement of the peripheral nervous system (Guillain Barré syndrome), which can present in any age group, between four and 23 days post vaccination $(1 ; 7)$. The CIG does not provide statistics on YEL-AND in Canadian vaccinees. The WHO reports that there have been 26 proven or probable cases of YEL-AND since 1945, with two fatalities (1). The CDC reports 0.8 cases per 100,000 doses of yellow fever vaccine administered (7). Studies suggest that older age is a risk factor for a serious adverse events including YEL-AND following yellow fever vaccination (41).

- Yellow Fever Vaccine Associated Viscerotropic Disease (YEL-AVD): YEL-AVD is characterized by severe illness and multi-organ failure, similar to that seen in yellow fever disease $(36 ; 42 ; 43)$. According to the $\mathrm{CIG}$, the risk of YEL-AVD increases with age: for those 60-69 years of age, the risk is estimated to be 1.0-1.1 per 100,000; for those 70 years or older, the risk is estimated to be 2.3-3.2 per 100,000 (38;41). According to the $\mathrm{WHO}$, risk of death from YEL-AVD is estimated to be one per 10 million doses of vaccine (1). Similar events were noted with five different preparations of 17D vaccine (44-46). Extensive investigations following a number of these cases suggest that this is due to various host factors, and not a change in virulence of the vaccine virus. Once again, the frequency of these severe (and often fatal) reactions is extremely low. These reactions have been linked to host characteristics including older age ( $\geq 60$ years) $(34 ; 41)$ and thymus disease associated with abnormal immune function (e.g. thymoma and myasthenia gravis ) (47), and are noted with primary vaccination. YEL-AVD tends to develop two to five days post-vaccination. There is no specific treatment for YEL-AVD except supportive care, usually in an intensive care setting $(11 ; 38 ; 42 ; 47)$.

Despite the emerging information on YEL-AND and YEL-AVD, the yellow fever vaccine is highly effective and safe. In the June 2008 meeting of the Global Advisory Committee on Vaccine Safety it was reiterated "that the recommendations for the use of yellow fever vaccine should remain unchanged" (48). The important message here is to ensure that the exact reason for vaccination is understood (risk of exposure versus international regulations). It is also crucial to avoid exposing travellers to the very small, but non-negligible, risk of yellow fever vaccination if there is no actual risk or requirement for vaccination $(7 ; 27 ; 48)$.

\section{Vaccine and special populations:}

Caution should be exercised in special groups as discussed below:

- Children: Children under the age of nine months typically should not be vaccinated against yellow fever (30). Preliminary studies $(30 ; 49 ; 50)$ suggest that although the incidence of adverse events in children older than six months does not appear to be significantly increased compared to infants greater than nine months of age, seroconversion is not optimal and there was still a small increase in adverse neurologic events in some small study populations. Children less than six months of age are at greater risk for YEL-AND $(1 ; 36)$. The Advisory Committee 
on Immunization Practices (ACIP) in the United States of America recommends that for children six to eight months old travelling to an endemic area, when travel is unavoidable, the decision to vaccinate needs to balance the risks of yellow fever virus exposure with the risk for adverse events following vaccination. For children under the age of six months, the vaccine is contraindicated (51).

- The older traveller: The aspect of primary vaccination in persons over 60 years of age has been discussed above with respect to the possibility of adverse events (YEL-AND and YEL-AVD). Discussion about the relative risk of vaccination versus the risk of contracting the disease should form the basis of any decision to vaccinate in this age group (7;36-38;41). Whereas the risk of an adverse outcome is small, it is not negligible. The best estimate of current disease prevalence/transmission in the country(ies) to be visited (based on the revised WHO/CDC vaccine recommendation maps), as well as the actual itinerary, should be assessed as accurately as possible. If there is a considerable risk of yellow fever transmission, then the decision to immunize can be made, understanding the small increased risk of serious adverse events. This decision is particularly important in those older travellers whose itineraries may take them to countries with strict yellow fever vaccination entry requirements, but little or no risk of actual disease exposure. If it is decided not to vaccinate based on minimal/no risk, then a waiver may be provided and personal protective measures against mosquitoes will need to be emphasized (see section 'Personal Protective Measures', below). Travellers will also have to be reminded that the need for vaccination must be re-evaluated for future travel to new destinations $(34 ; 41 ; 52-54)$.

- Pregnant women: As the effects of this live vaccine in pregnancy are not well documented, vaccination should be avoided if possible. If a pregnant woman must travel to a highly endemic or epidemic area, the risk of actually contracting the disease may outweigh the risks of vaccination to the mother or fetus $(7 ; 37)$. Preliminary surveys in the developing world have demonstrated some deleterious outcomes with respect to congenital transmission of disease and spontaneous abortion with vaccination (55-57), but these have been small studies. These have been counterbalanced by other studies showing no negative outcomes in pregnant women who were inadvertently vaccinated early in pregnancy (58-61). When travel is to a country that requires vaccine documentation in accordance with the IHR, but is not yellow fever endemic, a waiver should be provided rather than vaccination (4).
- Breastfeeding women: Until recently, there was only a theoretical risk of transmission of the live virus in breast milk. A recent incident in Brazil has now given laboratory confirmed evidence of yellow fever virus transmission in breast milk (62). As well, there was a case of a potential adverse outcome in an infant who was being breastfed by a mother who received yellow fever vaccination in Canada (63). These two cases should raise the level of caution when considering vaccinating women who are actively breastfeeding. Certainly, if there is no risk of acquiring yellow fever in the region to be visited, a waiver of vaccination should be given. If travel is to a highly endemic area, then the risks of vaccination will have to be weighed against the risk of disease $(37 ; 64)$.

- Immuno-compromised individuals: Travellers who have a disease causing lack of immune response or those on immune modulating medications should avoid vaccination with any live virus. In addition, their response to the antigen may not be sufficient to be protective. Yellow fever vaccine is contraindicated in individuals with severe underlying diseases such as leukemia, lymphoma, thymoma, generalized malignancy, gamma-globulin deficiency, symptomatic Human Immunodeficiency Virus (HIV) infections or Acquired Immunodeficiency Syndrome (AIDS) (CD4 count < 200 cells /ml) or those receiving significant immunosuppressive drugs (7;36;65-67). In these cases, travel to a yellow fever endemic area should be avoided. If travel is not avoidable, these patients should be counselled about insect precautions (see section 'Personal Protective Measures', below) and the risk of yellow fever transmission at their travel destination, and issued a vaccination waiver. There are data suggesting that individuals with asymptomatic HIV infection (CD4>200 cells $/ \mathrm{ml}$ or $15-24 \%$ of total cells in children< byears of age) can be administered the vaccine, but these individuals should be inoculated well in advance of travel in order to monitor potential adverse events, and neutralizing antibody titres should be considered to assess efficacy of the vaccination $(65 ; 68-71)$. Although study numbers are still small, use of yellow fever vaccine in persons with HIV have shown patients respond to the vaccine with lower neutralizing titres, more often demonstrate non-protective neutralizing titres and may experience a more rapid decline in these titres following vaccination. Also, the booster recommendations for immuno-competent travellers (i.e. every 10 years) are probably not adequate for those who are immuno-compromised. Neutralization titres or even revaccination at two to five years should be considered (72). There is no contraindication to vaccinating family members and travelling companions of immuno-compromised individuals as the virus is spread by mosquitoes, not person to person contact. Low dose 
steroids ( $<20 \mathrm{mg}$ prednisone equivalent or less than $2 \mathrm{mg}$ / $\mathrm{kg}$ in children under $10 \mathrm{~kg}$ ), topical steroid use or short-

term ( $<2$ weeks) steroid should not prevent vaccination (7). For more information, refer to the CATMAT statement on The Immunocompromised Traveller (73).

- Thymus disease: A review of deaths attributed to vaccination (YEL-AVD) has demonstrated an association with a history of thymus disease associated with abnormal immune function $(7 ; 36)$. These numbers are very small, but the association appears to be relevant and would preclude individuals with a history of thymoma, myasthenia gravis or thymectomy (for these conditions or unknown cause) from receiving yellow fever vaccine (74).

\section{Personal Protective Measures (PPM)}

All travellers should be advised on routine insect protection and precautions while travelling, regardless of yellow fever vaccination status. The mosquitoes that transmit yellow fever can be active throughout the day; therefore travellers should protect themselves against bites at all times. This is also good practice to prevent infection from other arthropod-borne diseases. For more information, refer to the CATMAT statement, "Personal Protective Measures to Prevent Arthropod Bites"(24). PPM as the sole prevention method would only be indicated for those at risk of contracting yellow fever, who cannot be vaccinated.

\section{Potential Consequences of Inappropriate Documentation}

Travellers must also be made aware that, even with a certificate or letter of yellow fever vaccine contraindication, they may still be denied entry or quarantined by border health and/or immigration authorities upon arrival at the destination country (19). Travellers also need to be counseled as to the potential risks of receiving local vaccination at the destination. 


\section{Summary of Recommendations}

TABLE 1: Strength and quality of evidence of summary (75)

\begin{tabular}{l|l}
\hline \multicolumn{2}{l}{ Categories for the strength of each recommendation } \\
\hline Category & Definition \\
\hline A & Good evidence to support a recommendation for use. \\
\hline B & Moderate evidence to support a recommendation for use. \\
\hline C & Poor evidence to support a recommendation for or against use. \\
\hline D & Moderate evidence to support a recommendation against use. \\
\hline E & Good evidence to support a recommendation against use. \\
\hline Categories for the quality of evidence on which recommendations are made \\
\hline Grade & Definition \\
\hline I & Evidence from at least one properly randomized, controlled trial. \\
\hline II & $\begin{array}{l}\text { Evidence from at least one well-designed clinical trial without randomization, from cohort or case-controlled } \\
\text { analytic studies, preferably from more than one centre, from multiple time series, or from dramatic results in } \\
\text { uncontrolled experiments. }\end{array}$ \\
\hline III & $\begin{array}{l}\text { Evidence from opinions or respected authorities on the basis of clinical experience, descriptive studies, } \\
\text { or reports of expert committees. }\end{array}$ \\
\hline
\end{tabular}

TABLE 2: Recommendations for the use of yellow fever vaccine by population

\begin{tabular}{|c|c|c|}
\hline Population & Pre-travel Recommendation & $\begin{array}{l}\text { Strength of } \\
\text { Evidence }\end{array}$ \\
\hline $\begin{array}{l}\text { Healthy adult travellers ( }<60 \text { years), travelling to an area where } \\
\text { yellow fever is considered endemic or transitional }\end{array}$ & Vaccination recommended. & A II \\
\hline $\begin{array}{l}\text { Healthy adult travellers (> } 60 \text { years), travelling to an area where } \\
\text { yellow fever is considered endemic or transitional presenting } \\
\text { for primary vaccination }\end{array}$ & $\begin{array}{l}\text { Careful assessment of risk recommended. } \\
\text { May vaccinate in cases of elevated risk of transmission. * }\end{array}$ & DII \\
\hline $\begin{array}{l}\text { Healthy children (>9 months) travelling to an area where yellow } \\
\text { fever is considered endemic or transitional }\end{array}$ & Vaccination recommended & A II \\
\hline Children less than 6 months of age & Vaccination contraindicated & E II \\
\hline Children between 6 and 9 months of age & $\begin{array}{l}\text { Careful assessment of risk recommended } \\
\text { May vaccinate in cases of elevated risk of transmission. * }\end{array}$ & DII \\
\hline Pregnant women & $\begin{array}{l}\text { Careful assessment of risk recommended } \\
\text { May vaccinate in cases of elevated risk of transmission. * }\end{array}$ & D॥ \\
\hline Breastfeeding women & $\begin{array}{l}\text { Careful assessment of risk recommended } \\
\text { May vaccinate in cases of elevated risk of transmission. * }\end{array}$ & DIII \\
\hline $\begin{array}{l}\text { Persons with asymptomatic HIV infection whose CD4 count is } \\
>200 \text { cells } / \mathrm{mm}^{3} \text { (or } 15-24 \% \text { of total cell in children<6years of age). }\end{array}$ & $\begin{array}{l}\text { Careful assessment of risk recommended } \\
\text { May vaccinate in cases of elevated risk of transmission. * }\end{array}$ & $B \|$ \\
\hline $\begin{array}{l}\text { Persons with a history of thymus disease associated with } \\
\text { abnormal immune function (e.g. thymoma or myasthenia gravis) }\end{array}$ & Vaccination contraindicated & E॥ \\
\hline $\begin{array}{l}\text { Immuno-compromised individuals (lymphoma, HIV (CD4 } \\
\text { count }<200 \text { cells } / \mathrm{mm}^{3} \text { ), immunosuppressive therapies, primary } \\
\text { immunosupression, autoimmune disorders) }\end{array}$ & Vaccination not recommended & E II \\
\hline $\begin{array}{l}\text { Persons with a life-threatening allergy to eggs } \\
\text { or chicken or other vaccine components }\end{array}$ & Vaccination contraindicated & E III \\
\hline
\end{tabular}

* Vaccination in these populations carries a potential of increased risk of adverse events (either to patient or offspring), and thus a general recommendation cannot be made. Consideration for vaccination must be done on a case-by-case basis. Delaying travel may be considered. If travel cannot be avoided and if the person is travelling to a highly endemic or epidemic area where the risk of yellow fever transmission is high, then the risks of contracting the disease may outweighed by the risks vaccination. Please see text for detailed discussion of vaccination in these groups. 


\section{Appendix 1: Yellow Fever Risk Areas}

APPENDIX 1A: Yellow fever risk classification criteria, $2011(20 ; 21)$

\begin{tabular}{|c|c|c|c|}
\hline Classification & Description & Risk of Infection & $\begin{array}{l}\text { Vaccination } \\
\text { Recommendation }\end{array}$ \\
\hline Endemic & $\begin{array}{l}\text { - Areas persistent of enzootic yellow fever virus transmission over } \\
\text { long periods of time } \\
\text { - Yellow fever vectors and non-human primate hosts present } \\
\text { - Yellow fever cases reported: human and non-human primate } \\
\text { - Yellow fever cases in humans before vaccine coverage } \\
\text { - Sero-surveys show evidence of high infection } \\
\text { - Stable transmission }\end{array}$ & High & Recommended \\
\hline Transitional & $\begin{array}{l}\text { - Areas bordering endemic zone with periodic evidence of } \\
\text { transmission during yellow fever epizootic or epidemic expansion } \\
\text { - Yellow fever vectors and non-human primate hosts present } \\
\text { - Human cases may be reported at long intervals } \\
\text { - Sero-surveys show past evidence of infection }\end{array}$ & Moderate to high & Recommended \\
\hline $\begin{array}{l}\text { Low potential } \\
\text { for exposure }\end{array}$ & $\begin{array}{l}\text { - Areas bordering yellow fever endemic or transitional areas } \\
\text { - Yellow fever vectors and non-human primates hosts present } \\
\text { - No human or non-human primate cases reported } \\
\text { - Sero-surveys may demonstrate past evidence of infection, } \\
\text { usually at low levels }\end{array}$ & Low & $\begin{array}{l}\text { Generally not } \\
\text { recommended* }\end{array}$ \\
\hline No risk & $\begin{array}{l}\text { - Areas where there is no risk of yellow fever transmission, as } \\
\text { determined by absence of past or present evidence of yellow } \\
\text { fever virus circulation in the area or environmental conditions } \\
\text { are not conducive to yellow fever transmission }\end{array}$ & No & Not recommended \\
\hline
\end{tabular}

* Vaccination might be considered for a small subset of travellers whose itineraries would place them at an increased risk for exposure to yellow fever virus (e.g., prolonged travel, with heavy exposure to mosquitoes, inability to avoid mosquito bites) 
APPENDIX 1B: Countries* ${ }^{*}$ with risk of yellow fever transmission by continent, 2011(27)

\begin{tabular}{|c|c|c|}
\hline \multicolumn{2}{|l|}{ Africa } & \multirow{2}{*}{$\begin{array}{l}\text { Central and South America } \\
\text { Argentina }^{\dagger}\end{array}$} \\
\hline Angola & Guinea & \\
\hline Benin & Guinea-Bissau & Bolivia $^{\dagger}$ \\
\hline Burkina Faso & Kenya & Brazil $^{\dagger}$ \\
\hline Burundi & Liberia & Colombia \\
\hline Cameroon & Mali $^{+}$ & Ecuador $^{\dagger}$ \\
\hline Central African Republic & Mauritania $^{\dagger}$ & French Guyana \\
\hline Chad $^{\dagger}$ & Niger $^{\dagger}$ & Guyana \\
\hline Congo & Nigeria & Panama $^{\dagger}$ \\
\hline Côte d'Ivoire & Rwanda & Paraguay \\
\hline Democratic Republic of the Congo & Senegal & Peru $^{\dagger}$ \\
\hline Equatorial Guinea & Sierra Leone & Suriname \\
\hline Ethiopia & Sudan ${ }^{\dagger}$ & Trinidad and Tobago ${ }^{\dagger}$ \\
\hline Gabon & Togo & Venezuela $^{\dagger}$ \\
\hline Gambia & Uganda & \\
\hline Ghana & & \\
\hline
\end{tabular}

* Designation of regions with risk of yellow fever transmission is subject to change. Travellers and health care providers should refer to current information available from the WHO at: www.who.int/ith/chapters/en

+ Countries in bold-type require proof of yellow fever vaccination and are subject to change. Additional countries require proof of yellow fever vaccination from travellers arriving from an endemic country. A complete listing of country-specific requirements is available from the CDC at: wwwnc.cdc.gov/travel or the WHO at: www.who.int/ith/chapters/en

+ Only a portion of the country has risk of yellow fever transmission. Refer to the WHO maps in Appendix 1c and Appendix 1d.

\section{APPENDIX 1C: Yellow fever vaccination recommendations in Africa, 2010 (21)}

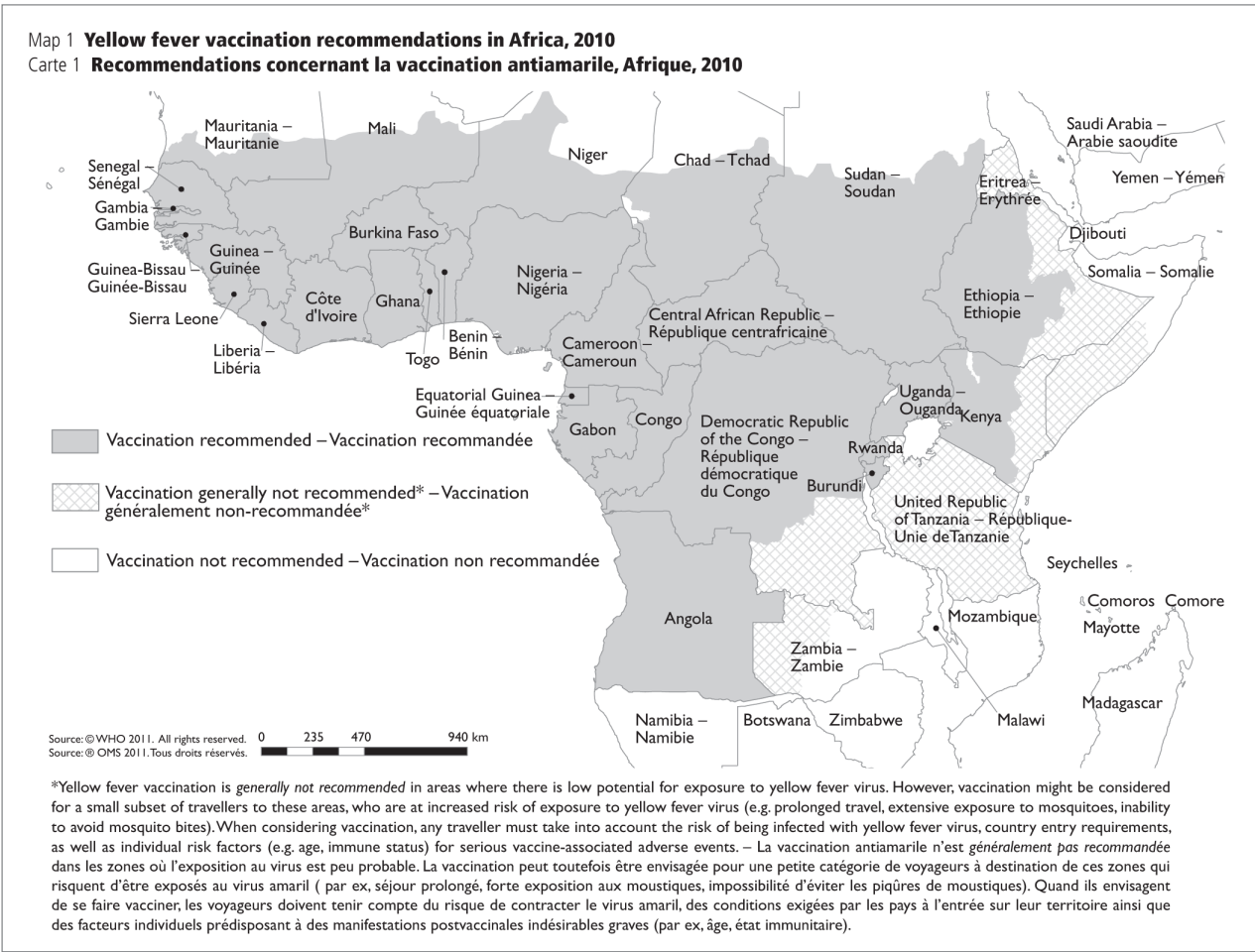


APPENDIX 1D: Yellow fever vaccination recommendations in the America, 2010 (21)

Map 2 Yellow fever vaccination recommendations in the Americas, 2010

Carte 2 Recommendations concernant la vaccination antiamarile, Amériques, 2010

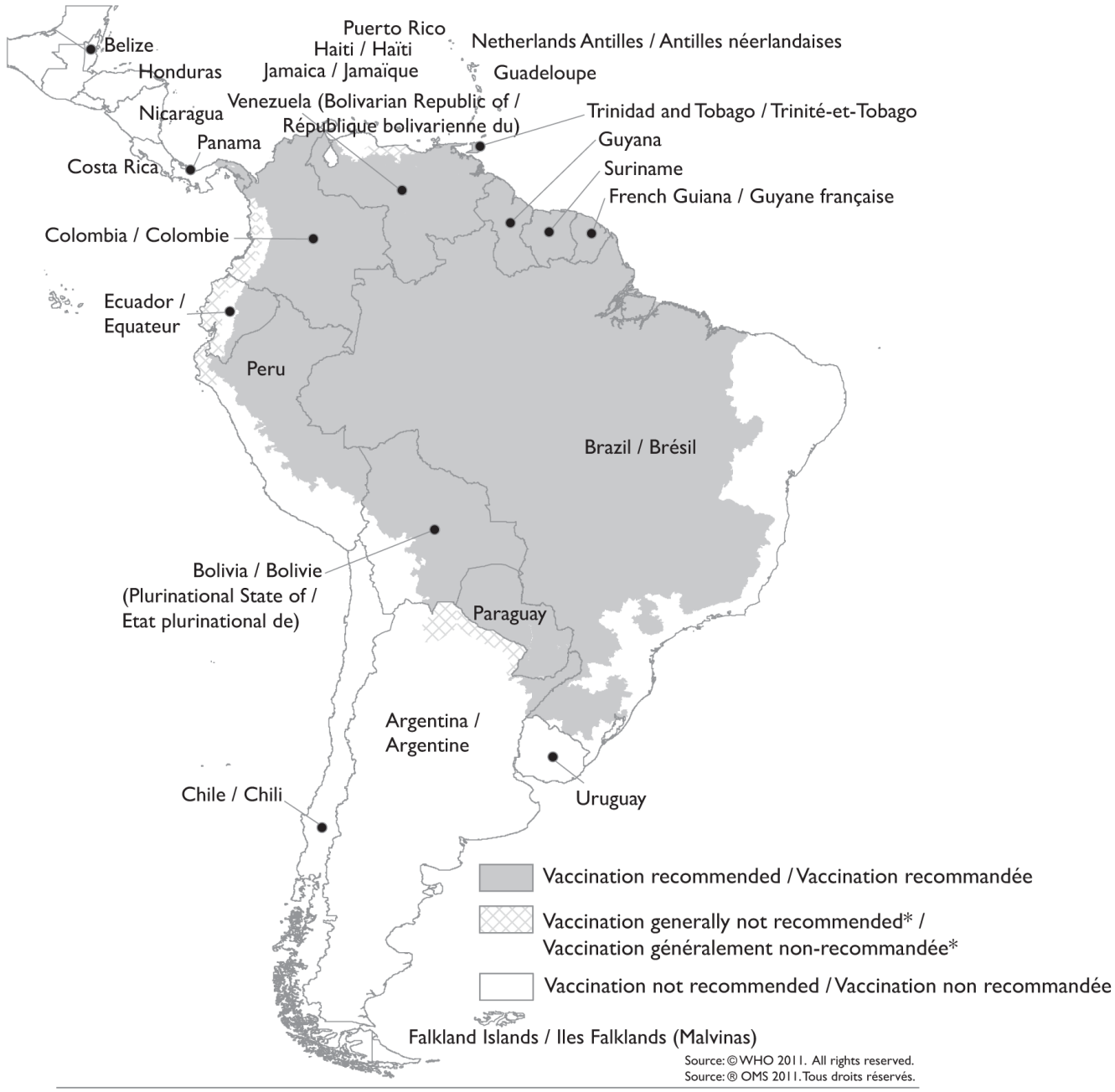

* Yellow fever vaccination is generally not recommended in areas where there is low potential for exposure to yellow fever virus. However, vaccination might be considered for a small subset of travellers to these areas, who are at increased risk of exposure to yellow fever virus (e.g. prolonged travel, extensive exposure to mosquitoes, inability to avoid mosquito bites). When considering vaccination, any traveller must take into account the risk of being infected with yellow fever virus, country entry requirements, as well as individual risk factors (e.g. age, immune status) for serious vaccine-associated adverse events.

* La vaccination antiamarile n'est généralement pas recommandée dans les zones où l'exposition au virus est peu probable. La vaccination peut toutefois être envisagée pour une petite catégorie de voyageurs à destination de ces zones qui risquent d'être exposés au virus amaril ( par ex, séjour prolongé, forte exposition aux moustiques, impossibilité d'éviter les piqûres de moustiques). Quand ils envisagent de se faire vacciner, les voyageurs doivent tenir compte du risque de contracter le virus amaril, des conditions exigées par les pays à l'entrée sur leur territoire ainsi que des facteurs individuels prédisposant à des manifestations postvaccinales indésirables graves (par ex, âge, état immunitaire). 


\section{Appendix 2: Yellow Fever Vaccination Centres in Canada}

Under Annex 7 of the International Health Regulations (2005), "States Parties shall designate specific yellow fever vaccination centres within their territories in order to ensure the quality and safety of the procedures and materials employed" (19). As a signatory to the International Health Regulations, Canada must designate Yellow Fever Vaccination Centres. This is coordinated by the Public Health Agency of Canada, contact information below.

Yellow Fever Vaccination Centres Program

Travel and Migration Health Division

Infectious Disease Prevention and Control Branch

Public Health Agency of Canada

380 Hunt Club Road, AL 6503B

Ottawa, Ontario, K1A OK9

E-Mail: yfinfofj@phac-aspc.gc.ca

Phone: (613) 957-8739

Fax: (613) 952-8286
For a list of the Yellow Fever Vaccination Centres, refer to the Public Health Agency of Canada's Web site at www.phac-aspc.gc.ca/tmp-pmv/yf-fj/index-eng.php. 


\section{APPENDIX 2A: Example of a Completed Copy of the International Certificate of Vaccination or Prophylaxis} Issued by the Public Health Agency of Canada

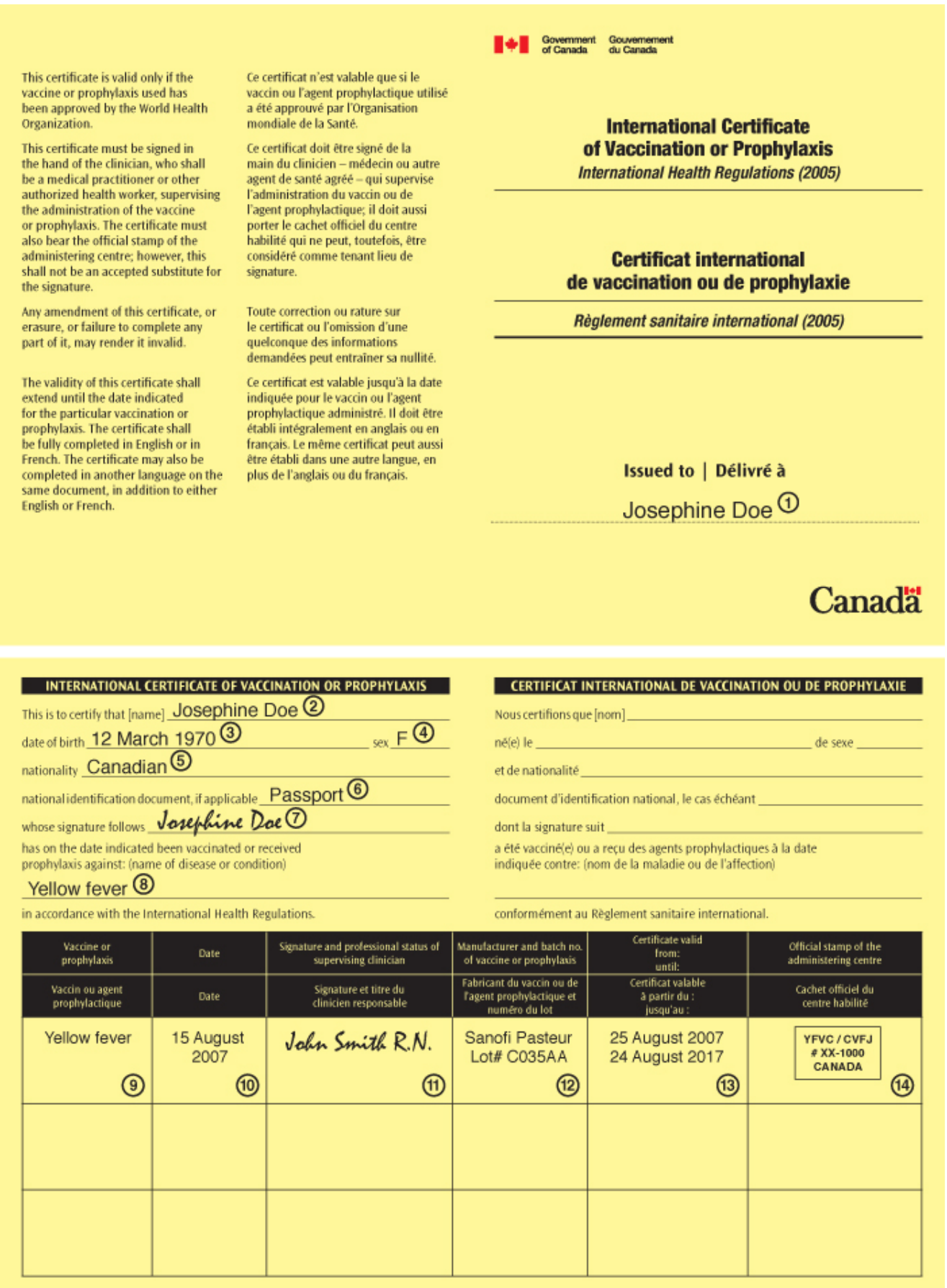

Although there are currently no internationally agreed-upon guidelines for the completion of the certificate, the Public Health Agency of Canada provides Yellow Fever Vaccination Centres recommendations to complete the certificate; for complete recommendations please refer to "Procedures for Yellow Fever Vaccination Centres in Canada (28)". 
APPENDIX 2B: Example of a Completed Copy of the Certificate of Medical Contraindication to Vaccination Issued by the Public Health Agency of Canada

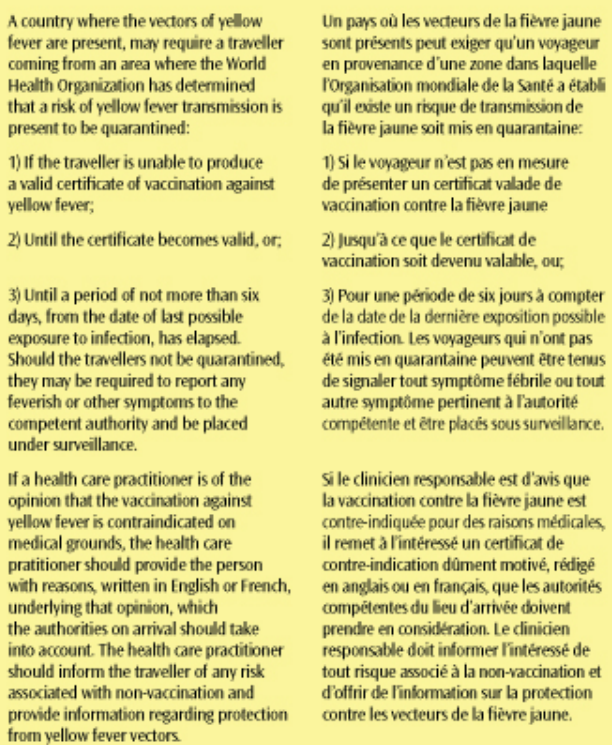

1) If the traveller is unable to produce a valid certificate of vaccination against yellow fever;

2) Until the certificate becomes valid, or;

3) Until a period of not more than six days, from the date of bas possible

exposure to infection, has elapsed.

Should the travellers not be quarantined.

they may be required to report any

competent authority and be placed under surveillance.

If a health care pracitioner is of the opinion that the vaccination again yellow fever is contraindicated on

medical grounds, the health care

pratitioner should provide the person

underlying that opinion, which

underlying that opinion, which

the authorities on amival should take -

ho account the health care pradisong

should intorm the traveller of any $n$ iss

provide information regarding protection

from yellow fever vectors

Un pałs où les vecteurs de la fière jaune Un pars où les vecteurs de la fievre jaune
sont présents peut exiger qu'un woyageur en provenance d'une zone dans laquelle rorganization mondiale de la santé a étabibi quill existe un risque de transmission de la fière jaune soit mis en quarantaine:

1) Si le voyageur n'est pas en mesure de presenter un certificat valade de vaccination contre la fièvre jaune

2) Jusqua à ce que le certificat de vacination soit devenu valable, our

3) Pour une période de six jours à compter de la date de la dernière exposition possible à l'infection Les voyageurs qui n'ont pas été mis en quarantaine peuvent être tenus de signaler tout symptôme fébrile ou tout autre symptôme pertinent a lautorité compétente et êre placés sous surveillance.

Si le clinicien responsable est d'avis que la vaccination contre la fièrre jaune est contre-indiquee pour des raisons médicale il remet a fintéressé un certificat de contre-indication dûment motivé, rédigé en anglais or en francaik que les autonits competentes du fieu dartree doven prescle en consideraibn. Le dimiden tout risque asociét ba mon doffir linforma contre les vecteurs de br fitve parce
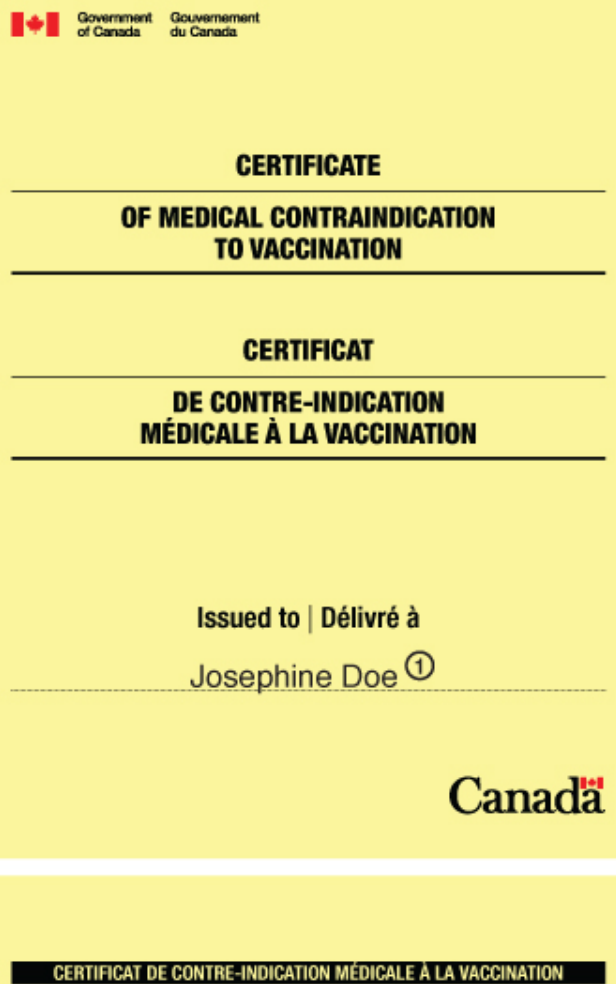

Nouscertifions que [nom]

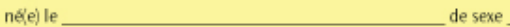

et de nationalité

document d'identification national, le cas échéant

dont la signature suit

ne peut être vaccinée) contre (nom de la maladie ou de l'affection)

pour la raison suivante:

Yellow fever (8)

because of the following reason:

Severe allergy to eggs (9)

\begin{tabular}{|c|c|c|c|c|}
\hline Contraindicated vaccine & Date & $\begin{array}{l}\text { Skerature and peofessional status } \\
\text { of supervising diniclan }\end{array}$ & $\begin{array}{l}\text { Medical contraindication } \\
\text { valid from: } \\
\text { until: }\end{array}$ & $\begin{array}{l}\text { Offidial stamp of the } \\
\text { administering centre }\end{array}$ \\
\hline Vaccin contre-indique & Date & $\begin{array}{l}\text { Signature et titre du } \\
\text { dinicien responsable }\end{array}$ & $\begin{array}{l}\text { Contre-indication médicale } \\
\text { à partir du: } \\
\text { jusqu'au: }\end{array}$ & $\begin{array}{l}\text { Cachet officiel du } \\
\text { centre habilite }\end{array}$ \\
\hline Yellow fever & 15 August 2007 & John Smith R.N. & $\begin{array}{c}25 \text { August } 2007 \\
30 \text { November } 2007\end{array}$ & $\begin{array}{l}\text { YFVC / CVFJ } \\
\text { XX-1000 } \\
\text { CANADA }\end{array}$ \\
\hline
\end{tabular}

In an effort to assist health care providers, the Public Health Agency of Canada provides Yellow Fever Vaccination Centres with Certificates of Medical Contraindication to Vaccination to document contraindications to the yellow fever vaccine. For complete recommendations on filling out this document please refer to "Procedures for Yellow Fever Vaccination Centres in Canada (28)". 


\section{References}

(1) World Health Organization. Yellow fever vaccine. WHO position paper. Weekly epidemiological record 2003;78(40):349-59.

(2) Monath TP. Yellow fever: An update. Lancet Infect Dis 2001;1(1):11-20.

(3) Heymann DL. Control of Communicable Diseases Manual 19th edition. Washington: American Public Health Association (APHA); 2008.

(4) World Health Organization. Fact Sheet: Yellow Fever. Geneva: WHO [website]. Available from: www.who.int/mediacentre/factsheets/fs100/en; 2011.

(5) Staples JE, Monath TP. Yellow fever: 100 Years of discovery. Journal of the American Medical Association 2008;300(8):960-2.

(6) World Health Organization. Yellow fever in the WHO African and American Regions, 2010. Weekly epidemiological record 2011;86(34):365-76.

(7) Centers for Disease Control and Prevention. CDC Health Information for International Travel 2012: The Yellow Book. Atlanta: U.S. Department of Health and Human Services, Public Health Service; 2011.

(8) World Health Organization. Progress in the control of yellow fever in Africa. Weekly epidemiological record 2005;80(6):50-5.

(9) World Health Organization. Yellow fever in Africa and Central and South America, 2008-2009. Weekly epidemiological record 2011;86(4):25-36.

(10) World Health Organization. Global Alert and Response: Yellow Fever. Geneva: WHO [website]. Available from: www.who.int/csr/disease/ yellowfev/en; 2011.

(11) Barnett ED. Yellow fever: Epidemiology and prevention. Clin Infect Dis 2007;44(6):850-6.

(12) McFarland JM, Baddour LM, Nelson JE, Elkins SK, Craven RB, Cropp BC, et al. Imported yellow fever in a United States citizen. Clin Infect Dis 1997;25(5):1143-7.

(13) Hall P, Fojtasek M, Pettigrove J, Perdue J, Hendricks K, Stanley S, et al. Fatal Yellow Fever in a traveler returning from Amazonas, Brazil, 2002. J Am Med Assoc 2002;287(19):2499-500.
(14) Centers for Disease Control and Prevention. Fatal yellow fever in a traveler returning from Venezuela, 1999. MMWR CDC Surveill Summ 2000;49(14):303-5.

(15) Bae HG, Drosten C, Emmerich P, Colebunders R, Hantson P, Pest $\mathrm{S}$, et al. Analysis of two imported cases of yellow fever infection from Ivory Coast and the Gambia to Germany and Belgium. J Clin Virol 2005;33(4):274-80.

(16) Public Health Agency of Canada. National Notifiable Diseases On-Line. Ottawa: PHAC [website]. Available from: http://dsol-smed.hc-sc.gc.ca/dsol-smed/ndis/ list-eng.php; 2005.

(17) Ellis BR, Barrett ADT. The enigma of yellow fever in East Africa. Rev Med Virol 2008;18(5):331-46.

(18) Behrens RH. Yellow fever recommendations for tourists to Kenya: A flawed risk assessment? J Travel Med 2008;15(5):285-6.

(19) World Health Organization. International Health Regulations (2005). 2 ed. Geneva: WHO; 2008.

(20) Jentes ES, Poumerol G, Gershman MD, Hill DR, Lemarchand J, Lewis RF, et al. The revised global yellow fever risk map and recommendations for vaccination, 2010: consensus of the Informal WHO Working Group on Geographic Risk for Yellow Fever. Lancet Infect Dis 2011 Aug;11(8):622-32.

(21) World Health Organization. Revised recommendations for the yellow fever vaccination for international travellers, 2011. Weekly epidemiological record 2011;86(37):401-16.

(22) Bae HG, Nitsche A, Teichmann A, Biel SS, Niedrig M. Detection of yellow fever virus: A comparison of quantitative real-time PCR and plaque assay. J Virol Methods 2003;110(2):185-91.

(23) Vazquez S, Valdes O, Pupo M, Delgado I, Alvarez M, Pelegrino J, et al. MAC-ELISA and ELISA inhibition methods for detection of antibodies after yellow fever vaccination. J Virol Methods 2003;110(2):179-84.

(24) Committee to Advise on Tropical Medicine and Travel. Statement on Personal Protective Measures to Prevent Arthropod Bites - Update. Can Commun 2012 Nov;38(ACS-3):1-18. 
(25) Mutebi JP, Barrett ADT. The epidemiology of yellow fever in Africa. Microbes Infect 2002;4(14):1459-68.

(26) Reiter P, Cordellier R, Ouma JO, Cropp CB, Savage HM, Sanders EJ, et al. First recorded outbreak of yellow fever in Kenya, 1992-1993. II. Entomologic investigations. Am J Trop Med Hyg 1998;59(4):650-6.

(27) World Health Organization. International Travel and Health: Situation as on 1 January 2011. Geneva: WHO; 2011.

(28) Public Health Agency of Canada. Procedures for Yellow Fever Vaccination Centres in Canada. Ottawa: Her Majesty the Queen in Right of Canada; 2011.

(29) Poland JD, Calisher CH, Monath TP, Downs WG, Murphy K. Persistence of Neutralizing Anitbody 30-35 Years After Immunization with 17D Yellow Fever Vaccine. Bulletin of the World Health Organization 1981;59(6):895-900.

(30) Sanofi Pasteur. Product Monograph YF-VAX® Yellow Fever Vaccine. Toronto: Sanofi-Pasteur Ltd; 2009.

(31) Choudri Y, Walop W. Review of adverse events reported following use of yellow fever vaccineCanada, 1987-2000. Can Commun Dis Rep 2002;28(2):9-15.

(32) World Health Organization. Adverse events following yellow fever vaccination. Weekly epidemiological record $2001 ; 76(29): 217-8$.

(33) Levy S, Mullane K, Miller M, Siva S, Barnes D, Dhaliwal $P$, et al. Adverse events associated with 17D-derived yellow fever vaccination - United States, 2001-2002. MMWR CDC Surveill Summ 2002;51(44).

(34) Lawrence GL, Burgess MA, Kass RB. Age-related risk of adverse events following yellow fever vaccination in Australia. Commun Dis Intell 2004;28(2):244-8.

(35) Lawrence G, Menzies R, Burgess M, Mclntyre P, Wood N, Boyd I, et al. Surveillance of adverse events following immunisation: Australia, 2000-2002. Commun Dis Intell 2003;27(3):307-23.

(36) Barrett ADT, Monath TP, Barban V, Niedrig M, Teuwen DE. 17D yellow fever vaccines: New insights. A report of a workshop held during the World Congress on Medicine and Health in the Tropics, Marseille, France, Monday 12 September 2005. Vaccine 2007;25(15):2758-65.
(37) Public Health Agency of Canada. Canadian Immunization Guide. Evergreen Edition; Part 4: Active Vaccines, Yellow Fever Vaccine. Ottawa: PHAC [website]. Available from: www.phac-aspc.gc.ca/ publicat/cig-gci/p04-yfev-fiej-eng.php; 2012

(38) Lindsey NP, Schroeder BA, Miller ER, Braun MM, Hinckley AF, Marano N, et al. Adverse event reports following yellow fever vaccination. Vaccine 2008;26(48):6077-82.

(39) Kelso JM, Mootrey GT, Tsai TF. Anaphylaxis from yellow fever vaccine. J Allergy Clin Immunol 1999;103(4):698-701.

(40) Tounian P, Delacourt C, De Blic J, Paupe J, Scheinmann P. Administration of egg-containing vaccines to egg-allergic children. Arch Fr Pediatr 1993;50(3):191-5.

(41) Khromava AY, Eidex RB, Weld LH, Kohl KS, Bradshaw RD, Chen RT, et al. Yellow fever vaccine: An updated assessment of advanced age as a risk factor for serious adverse events. Vaccine 2005;23(25):3256-63.

(42) Hayes EB. Acute viscerotropic disease following vaccination against yellow fever. Trans $\mathrm{R}$ Soc Trop Med Hyg 2007;101(10):967-71.

(43) Munoz J, Vilella A, Domingo C, Nicolas JM, De Ory F, Corachan M, et al. Yellow fever-associated viscerotropic disease in Barcelona, Spain. J Travel Med 2008;15(3):202-5.

(44) Kitchener S. Viscerotropic and neurotropic disease following vaccination with the 17D yellow fever vaccine, ARILVAX. Vaccine 2004;22(17-18):2103-5.

(45) Martin M, Tsai TF, Cropp B, Chang GJJ, Holmes DA, Tseng J, et al. Fever and multisystem organ failure associated with 17D-204 yellow fever vaccination: A report of four cases. Lancet 2001;358(9276):98-104.

(46) Belsher JL, Gay P, Brinton M, DellaValla J, Ridenour R, Lanciotti $R$, et al. Fatal multiorgan failure due to yellow fever vaccine-associated viscerotropic disease. Vaccine 2007;25(50):8480-5.

(47) Centers for Disease Control and Prevention. Fever, jaundice, and multiple organ system failure associated with 17D-derived yellow fever vaccination, 1996-2001. MMWR CDC Recomm Rep 2001;50(30): 643-5. 
(48) World Health Organization. Meeting of Global Advisory Committee on Vaccine Safety, 18-19 June 2008. Weekly epidemiological record 2008 Aug 8;83(32):287-92.

(49) Osinusi K, Akinkugbe FM, Akinwolere OA, Fabiyi A. Safety and efficacy of yellow fever vaccine in children less thanone-year-old. West Afr J Med 1990;9(3):200-3.

(50) Sood SK. Immunization for children traveling abroad. Pediatr Clin North Am 2000;47(2):435-48.

(51) Advisory Committee on Immunization Practices. Yellow Fever Vaccine - Recommendations of the Advisory Committee on Immunization Practices. MMWR Morb Mortal Wkly Rep 2010;59(7):1-27.

(52) Leder K, Weller PF, Wilson ME. Travel vaccines and elderly persons: Review of vaccines available in the United States. Clin Infect Dis 2001;33(9):1553-66.

(53) Monath TP, Cetron MS, McCarthy K, Nichols R, Archambault WT, Weld L, et al. Yellow fever 17D vaccine safety and immunogenicity in the elderly. Hum Vaccin 2005;1(5):207-14.

(54) Martin M, Weld LH, Tsai TF, Mootrey GT, Chen RT, Niu M, et al. Advanced age a risk factor for illness temporally associated with yellow fever vaccination. Emerg Infect Dis 2001;7(6):945-51.

(55) Nishioka SDA, Nunes-Araùjo FRF, Pires WP, Silva FA, Costa HL. Yellow fever vaccination during pregnancy and spontaneous abortion: A case-control study. Trop Med Int Health 1998;3(1):29-33.

(56) Robert E, Vial T, Schaefer C, Arnon J, Reuvers M. Exposure to yellow fever vaccine in early pregnancy. Vaccine 1999;17(3):283-5.

(57) Tsai TF, Paul R, Lynberg MC, Letson GW. Congenital yellow fever virus infection after immunization in pregnancy. J Infect Dis 1993;168(6):1520-3.

(58) Nasidi A, Monath TP, Vandenberg J, Tomori O, Calisher $\mathrm{CH}$, Hurtgen $\mathrm{X}$, et al. Yellow fever vaccination and pregnancy: A four-year prospective study. Trans R Soc Trop Med Hyg 1993;87(3):337-9.

(59) Suzano CES, Amaral E, Sato HK, Papaiordanou PM, Marba S, Pessoto M, et al. The effects of yellow fever immunization (17DD) inadvertently used in early pregnancy during a mass campaign in Brazil. Vaccine 2006;24(9):1421-6.
(60) Cavalcanti DP, Salom+úo MA, Lopez-Camelo J, Pessoto MA, Sato H, Amaral EM, et al. Early exposure to yellow fever vaccine during pregnancy. Trop Med Int Health 2007;12(7):833-7.

(61) D'Acremont V, Tremblay S, Genton B. Impact of vaccines given during pregnancy on the offspring of women consulting a travel clinic: A longitudinal study. J Travel Med 2008;15(2):77-81.

(62) Centers for Disease Control and Prevention. Transmission of Yellow Fever Vaccine Virus Through Breast-Feeding - Brazil, 2009. MMWR Morb Mortal Wkly Rep 2010;59(5):130-2.

(63) Kuhn S, Twele-Montecinos L, MacDonald J, Webster P, Law B. Case report: probable transmission of vaccine strain of yellow fever virus to an infant via breast milk. CMAJ 2011 Mar 8;183(4):E243-E245.

(64) Cetron MS, Marfin AA, Julian KG, Gubler DJ, Sharp DJ, Barwick RS, et al. Yellow fever vaccine. Recommendations of the Advisory Committee on Immunization Practices (ACIP), 2002. MMWR Recomm Rep 2002;51(RR-17):1-11.

(65) Bruyand $\mathrm{M}$, Receveur MC, Pistone $\mathrm{T}$, Verdière $\mathrm{CH}$, Thiebaut R, Malvy D. Yellow fever vaccination in non-immunocompetent patients. Med Mal Infect 2008;38(10):524-32.

(66) Cohn J, Blumberg EA. Immunizations for renal transplant candidates and recipients. Nat Clin Pract Nephrol 2009;5(1):46-53.

(67) Sester M, Gärtner BC, Girndt M, Sester U. Vaccination of the solid organ transplant recipient. Transpl Rev 2008;22(4):274-84

(68) Receveur MC, Thiébaut R, Vedy S, Malvy D, Mercié $\mathrm{P}$, Bras ML. Yellow fever vaccination of human immunodeficiency virus-infected patients: report of 2 cases. Clinical infectious diseases : an official publication of the Infectious Diseases Society of America 2000;31(3):E7-E8.

(69) Gowda R, Cartwright K, Bremner JAG, Green ST. Yellow fever vaccine: A successful vaccination of an immunocompromised patient. Eur J Haematol 2004;72(4):299-301. 
(70) Tattevin P, Depatureaux AG, Chapplain JM, Dupont M, Souala F, Arvieux C, et al. Yellow fever vaccine is safe and effective in HIV-infected patients. AIDS 2004;18(5):825-7.

(71) Pistone T, Verdiere CH, Receveur MC, Ezzedine K, Lafon ME, Malvy D. Immunogenicity and tolerability of yellow fever vaccination in 23 French HIV-infected patients. Curr HIV Res 2010 Sep 1;8(6):461-6.

(72) Veit O, Niedrig M, Chapuis-Taillard C, Cavassini M, Mossdorf E, Schmid P. Immunogenicity and safety of yellow fever vaccination for 102 HIV-infected patients. Clin Infect Dis 2009;48(5):659-66.

(73) Committee to Advise on Tropical Medicine and Travel. The immunocompromised traveller. Can Comm Dis Rep 2007;33(ACS-4):1-24.

(74) Barwick R. History of thymoma and yellow fever vaccination. Lancet 2004;364(9438):936.

(75) Committee to Advise on Tropical Medicine and Travel. Evidence-based medicine. Can Comm Dis Rep 1994;20(17):145-7. 